\title{
Automation in multiresidue analysis
}

\section{of pesticides using on-line solid-phase extraction and liquid chromatography}

\begin{abstract}
M.-C. Hennion 10 rue Vauquelin, 75231 Paris Cedex 05, France

Automatic devices which couple on-line the sample pretreatment by solid-phase extraction and the liquid chromatographic separation in one analytical run are nowadays commercially available. This represents a fast, modern and reliable approach for monitoring pesticides over a wide range of polarity.
\end{abstract}

École Supérieure de Physique et de Chimie Industrielles (ESPCI), Laboratoire Environnement et Chimie Analytique (ERS CNRS 657), ery unit (SDU) provides the solvents necessary to purge, wash, and activate the precolumn. After conditioning, sample application, and eventual clean-up via the pump of the SPE part, the precolumn is placed in front of an analytical column by switching the valve into the "inject" position. The trapped compounds are then eluted directly from the precolumn into the analytical column by a suitable mobile phase allowing the chromatographic separation of the extracted analytes. Quantitative results of good accuracy can be expected as there is no sample manipulation between the preconcentration and the analysis. The LC system is often run in the reversed-phase mode, using $\mathrm{C}_{18}$ analytical columns because the mobile phase is a partly aqueous solvent mixture. Therefore, residual water in the precolumn after the preconcentration of aqueous samples does not have to be removed before the desorption. The addition of a second switching valve allows both direct injection onto the analytical column and preconcentration via the precolumn. Automation is very easy and several devices are now commercially available (such as the Prospekt from Spark Holland, and OSP-2 from Merck). In these systems, a new disposable precolumn is used for each run and the exchange is automatic. The whole sequence can be programmed and can be performed on a sample whilst the on-line analysis of a previous sample occurs [10-18]. This full automation has been used for on-site monitoring of pesticides in surface waters as part of an early warning alarm system $[8,13,17$ 20]. These studies have contributed greatly in demonstrating that on-line SPE-LC is a robust and reliable technique that can be applied routinely in the field.

The quality of the coupling can easily be controlled by comparing chromatograms obtained by direct injection with those obtained by on-line preconcentration via the precolumn. The dimensions of the precolumn should be adapted to those of the analytical column and are typically 2 $15 \mathrm{~mm}$ long and $1-4.6 \mathrm{~mm}$ I.D. for a classical 15 $25 \mathrm{~cm}$ long analytical column. The size of the precolumn is an important parameter because the profile of the concentrated species transferred from the precolumn to the analytical column should be as narrow as possible at the beginning of the separation in order to avoid band-broadening. Although it was first recommended to pack precolumns with $5-10 \mu \mathrm{m}$ packings [5], the trend now is to use $15-40 \mu \mathrm{m}$ packings in order to have a high sampling rate during the loading of the sample and to prevent clogging with, for example, a surface-water sample. Despite the granulometry, one is recommended to use LC-grade- and pressure-resistant sorbents. Prepacked precolumns with different sorbents are now available from various manufacturers. It is also easy to pack a precolumn in the laboratory, thus allowing the potential of using new sorbents.
The on-line set-up coupling SPE to LC is particularly easy to perform in any laboratory, and has been described extensively in general reviews [1-9]. The apparatus is represented in figure 1 [10]. The trace-enrichment is carried out on a small precolumn, generally made of stainless steel in order to be pressure-resistant, which is placed at the sample-loop position of a six-port liquid switching valve. A solvent deliv- 

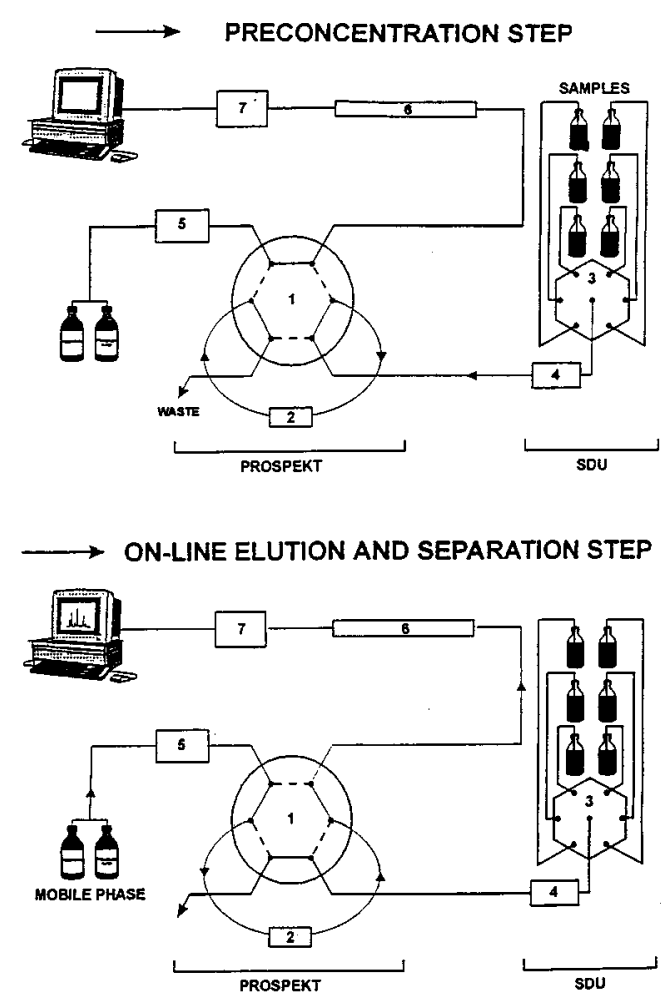

Figure 1. On-line set-up. 1: LC switching valve, 2: precolumn, 3: switching valve of the solvent delivery unit, 4: preconcentration pump, 5: LC pump, 6: analytical column, 7: detector.

Backflush-desorption of the precolumn should give the least amount of extra band-broadening but has also the drawback of creating problems of clogging of the analytical column when real samples are used. In the forward-desorption mode, the precolumn has the additional role of acting as a guard column and thus preserving the life-time of the analytical column.

\section{Selection of the sorbent in the precolumn}

The compatibility between the sorbent and the precolumn is important. The most efficient system is ideally obtained for a precolumn and an analytical column of the same nature [5]. But, a serious limitation of SPE-LC systems is that they use small precolumns which therefore contain a small amount of sorbent. In contrast to off-line SPE where there is the possibility of increasing the breakthrough volumes, $V_{\mathrm{b}}$, by increasing the amount of sorbent in the cartridge, in online SPE, when compounds are poorly retained the only solution is to select a more retentive sorbent. For an average LOD of $5 \mathrm{ng}$, if one wants determination in water at a concentration of $1 \mu \mathrm{g} / \mathrm{L}$, a sample volume of $5 \mathrm{~mL}$ will be sufficient. In real water samples, the presence of humic substances and other contaminants will often require the handling of a 10-fold higher volume. When determination at levels of $50 \mathrm{ng} / \mathrm{L}$ are required, the sample volume should be increased to at least $100-150 \mathrm{~mL}$.
Table I compares the recoveries obtained when handling $200 \mathrm{~mL}$ samples through commercial precolumns of $10 \mathrm{~mm}$ $\times 2 \mathrm{~mm}$ I.D. packed with $\mathrm{C}_{8}, \mathrm{C}_{18}$ and an apolar styrene divinylbenzene (SDB) copolymer PLRP-S [21]. The limitation of using $\mathrm{C}_{18}$ silica in conventional on-line precolumns for the preconcentration of the more polar pesticides is demonstrated by low recovery data. The classification of pesticides by increasing hydrophobicity is a great help in rapidly estimating whether $\mathrm{C}_{18}$ will be the appropriate sorbent, depending on the trace-level required $[1,2,22]$.

As expected the SDB polymer provides the highest recoveries. This polymer is often selected for mutltiresidue analysis containing pesticides over a wide range of polarity. Figure 2 shows the chromatograms corresponding to the one-line analysis of $150 \mathrm{~mL}$ of a drinking water sample originating from ground water, non-spiked in figure $2 \mathrm{a}$ and spiked with $0.1 \mu \mathrm{g} / \mathrm{L}$ of a mixture containing 21 pesticides with a wide range of polarities [10]. Although breakthrough has occurred for de-ethylatrazine, there was no problem in identifying de-ethylatrazine at a concentration of $0.09 \pm$ $0.01 \mu \mathrm{g} / \mathrm{L}$ in such waters. De-isopropylatrazine is part of polar solutes which become difficult to determine at the 0.1 $\mu \mathrm{g} / \mathrm{L}$ level, owing to its too early breakthrough. Another advantage of copolymer sorbents over $\mathrm{C}_{18}$ silica is that they can be used in the $\mathrm{pH}$ range 1-13.

When pesticides over a wide range of polarity are analysed on-line losses can occur for the more polar ones, as results of breakthrough, but losses can also occur for the more apolar one as results of adsorption in connection and sample bottles, as in off-line methods. One example was reported in the screening of organophosphorus pesticides [19]. This class of compounds is often analysed by GC but contains some thermolabile compounds. With the handling of $100 \mathrm{~mL}$ samples and using a PLR-S precolumn, excellent recoveries were obtained for the medium polarity compounds and lower recoveries were observed for the more polar compounds such as monocrotophos $(15 \%)$ and vamidothion $(70 \%)$ due to breakthrough. But, recoveries around

Table I. Percent recovery of pesticides using cartridges packed with different phase material (sample volume 200 $\mathrm{mL}$, precolumn size: $10 \times 2 \mathrm{~mm}$ I.D.). Adapted from reference [21].

\begin{tabular}{lccc}
\hline Phase & $C_{8}$ & $C_{18}$ & PLRP-S \\
\hline Compound & & & \\
De-isopropylatrazine & 15 & 30 & 55 \\
Desethylatrazine & 20 & 32 & 60 \\
Metoxuron & 20 & 56 & 95 \\
Simazine & 25 & 60 & 97 \\
Monuron & 10 & 35 & 98 \\
Chlortoluron & 45 & 80 & 97 \\
Atrazine & 75 & 85 & 97 \\
Isoproturon & 75 & 81 & 92 \\
Diuron & 50 & 75 & 95 \\
Metobromuron & 35 & 75 & 97 \\
Terbutylazine & 70 & 90 & 97 \\
Linuron & 80 & 89 & 95 \\
Metolachlor & 80 & 89 & 95 \\
Neburon & 85 & 90 & 97 \\
\hline
\end{tabular}




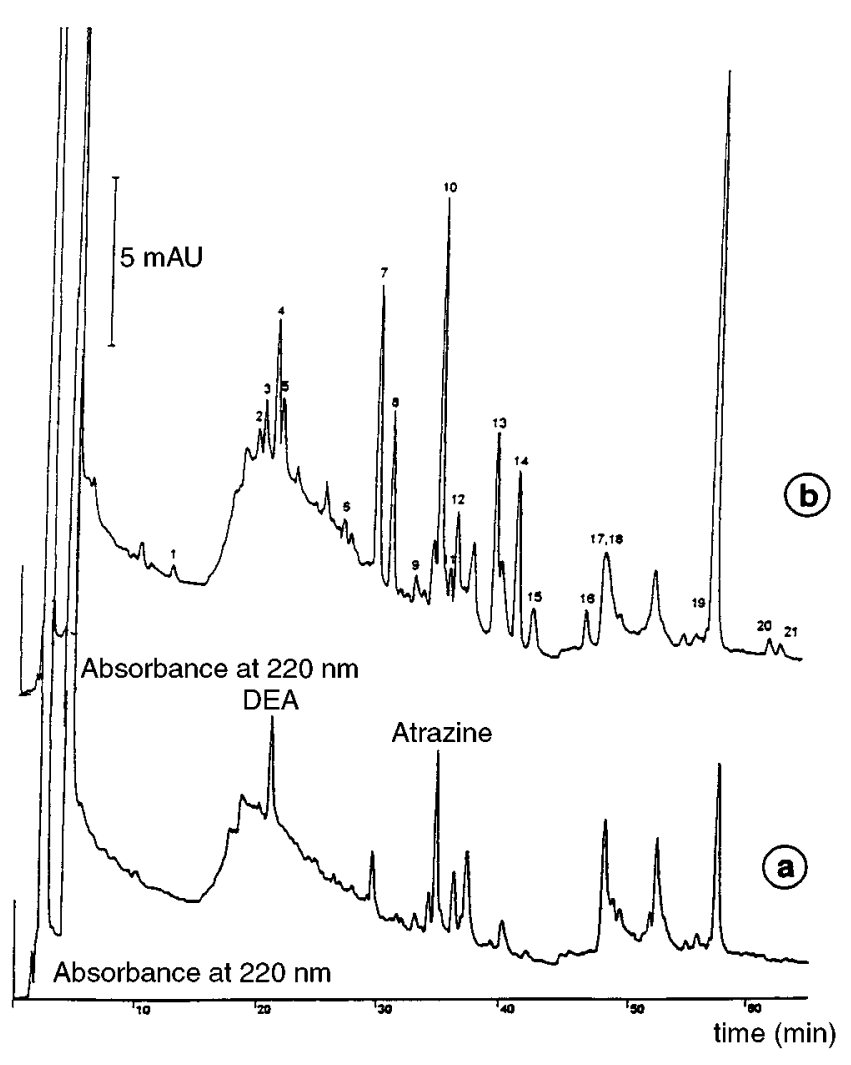

Figure 2. On-line analysis of; a) $150 \mathrm{~mL}$ of a drinking-water sample, and b) $150 \mathrm{~mL}$ of the same sample spiked with $0.1 \mu \mathrm{g} / \mathrm{L}$ of a mixture of 21 pesticides using the Prospekt system. From reference [2]. Precolumn: $1 \mathrm{~cm} \times 0.2 \mathrm{~cm}$ I.D. packed with PLRP$S$ from Polymer Laboratories; $C_{18}$ analytical column ODS-80TM, $25 \mathrm{~cm} \times 0.46 \mathrm{~cm}$ I.D., water-acetonitrile gradient: $15 \% \mathrm{ACN}$ from 0 to $10 \mathrm{~min}, 50 \%$ at $33 \mathrm{~min}, 50 \%$ at $\mathbf{4 0} \mathrm{min}, 70 \%$ at $70 \mathrm{~min}$; UV DAD detection, chromatogram at $220 \mathrm{~nm}$. Peak numbers: (1) deisopropylatrazine; (2) metamitron; (3) hydroxyatrazine; (4) deethylatrazine; (5) chloridazon; (6) aldicarb; (7) simazine; (8) deethylterbutylazine; (9) carbofuran; (10) atrazine; (11) isoproturon; (12) diuron; (13) propazine; (14) terbutylazine; (15) linuron; (16) terbuconazole; (17) alachlor; (18) metolachlor; (19) fenoxaprop-p-ethyl; (20) pendimethalin; (21) trifluralin. using mobile phases which contain a high proportion of water but which are unable to desorb the polar analytes trapped on the SDB precolumn [24]. More retentive analytical columns should be used to solve this problem. Recent commercially available polymeric columns were shown to be efficient, but their specific area is low and consequently, for very polar compounds, retention factors are very similar to those obtained with $\mathrm{C}_{18}$ silica columns. The possibility of coupling precolumn packed with high surface area SDB with an analytcal porous graphitic analytical columns allowed the determination of clopyralid, oxamyl, dicamba, monocrotophos and other very polar pesticides at the $0.1 \mu \mathrm{g} / \mathrm{L}$ level from $100 \mathrm{~mL}$ samples [24].

Porous graphitic carbon is of interest because of its suitability to trap very polar analytes [26]. But some band broadening occurs when coupling a PGC precolumn to a $\mathrm{C}_{18}$ column for the same reasons as those occcuring when coupling a SDB precolumn. This is not due to the carbon because on-line systems using a PGC precolumn and an analytical PGC column have been described [25,27-29].

Ion-exchangers should be appropriate sorbents for selectively trapping ionic pesticides. Cation-exchangers have been used for the on-line preconcentration of aniline derivatives [30]. However, it was shown that when a sample is percolated through cation-exchanger sorbents and one is looking for less than $1 \mu \mathrm{g} / \mathrm{L}$ of an organic cation, the much higher amounts of inorganic cations which are present in natural waters rapidly overload the cation-exchanger capacity. A chemical clean-up pretreatment consisting of oxalate precipitation of calcium ions, then EDTA complexation of metal ions, has been described for removing most of the inorganic cations before preconcentration [30]. Nevertheless, overloading still occurs rapidly, as demonstrated by the preconcentration study on aminotriazole [31]. When this analyte was dissolved in deionized LC-grade waters, the breakthrough was measured as $150 \mathrm{~mL}$, using a $1 \mathrm{~cm} \times 0.2 \mathrm{~cm}$ I.D. precolumn packed with a polymer-based cationexchanger. It was below $30 \mathrm{~mL}$ with drinking water samples, after the chemical preatreatment described above. In other work, a low volume $-10 \mathrm{~mL}$ - was percolated through an ion-pair-exchanger sorbent for the determination of aniline and chloridazon, without chemical pretreatment for the removal of anionic inorganic compounds [32].

\section{Precolumns in series}

bromophos ethyl due to adsorption problems in the inner walls of the connective tubing and the seals of the switching valves of the preconcentration system. This underlines the inherent problem in analysing compounds over too large a range of polarity because asdorption can be minimised only by adding a surfactant or an organic solvent which has the effect of increasing the losses of the more polar compounds.

New SDB with high specific surface areas have been shown to strongly retain polar analytes [23,24]. The problem is that the on-line coupling with a $\mathrm{C}_{18}$ analytical column is difficult for on-line analysis of very polar analytes because the difference in retention by the two sorbents is too large. Large band broadening has been observed using a SDB precolumn whereas this did not appear using a $\mathrm{C}_{18}$ precolumn [25]. The band broadening was explained by the fact that polar analytes can only be separated on $\mathrm{C}_{18}$ columns by
The on-line configuration usually includes a single precolumn. However there are many examples where more selectivity can be obtained by using two precolumns. For compounds that are ionizable in the $\mathrm{pH}$ range $2-10$, direct percolation of samples through ion-exchanger sorbents can be avoided by using a two-step preconcentration. It is based on the fact that solutes are retained on a SDB sorbent when in their neutral form but not in their ionic form. This approach was applied to chlorotriazines and their hydroxylated derivatives which have ionization constants around 2 and 5 respectively [33]. The water sample, adjusted to $\mathrm{pH}$ 7 , was percolated through a single SDB (PRP-1) precolumn. Then, this precolumn was coupled to a second one packed with the cation-exchanger precolumns and a small volume of deionized water containing $25 \%$ acetonitrile, adjusted to 
$\mathrm{pH}$ 1, allowed the triazine herbicides to be desorbed from the PRP-1 precolumn, transferred and re-concentrated on the cation-exchanger precolumns. This second precolumn was then eluted on-line. Detection limits below $0.1 \mu \mathrm{g} / \mathrm{L}$ could easily be obtained in surface-water samples.

Anion-exchangers have also been combined with PRP-1 for a two-step preconcentration. Applications to phenol and phenoxyacid herbicides have been presented [34-36].

\section{Reproducibility and robustness of the method}

One advantage of automation in on-line preconcentration is that more reproducible results can be expected, provided the precolumns are packed with the same amount of sorbent and have the same efficiency. The overall reproducibility of the method includes both the reproducibility of the preconcentration and of the LC system. The repeatability of peak-areas and heights obtained by direct-loop injections into the analytical column has been studied, using an acetonitrile gradient for the analytical separation. The relative standard deviation (RSD) was between 3 and $7 \%$, and 3 and 5\% for measurements of peak areas and peak heights, respectively [14]. In the same study, the reproducibility between cartridges was measured by preconcentrating $50 \mathrm{~mL}$ of LCgrade water spiked with $0.5 \mu \mathrm{g} / \mathrm{L}$ of pesticides, using a Prospekt system with a new precolumn packed with the PLRP-S copolymer in each run. The RSD was around 10\% $(n=5)$ for measurements of both peak areas and peak heights. RSD values below $10 \%$ have been also confirmed in other studies, thus indicating that the precolumns were packed under reproducible conditions. The flow-rate applied for the preconcentration varied from 1 to $5 \mathrm{~mL} / \mathrm{min}$ and the same average $10 \%$ RSD was observed [18].

In the framework of the Rhine Basin programme, an automated LC monitoring system (SAMOS-LC, or System for Automated Monitoring of Organic compounds in Surface waters) has been studied extensively. The procedure includes the loading of $100-150 \mathrm{~mL}$ of surface water onto PLRP$\mathrm{S}$ precolumns of a Prospekt device at $5 \mathrm{~mL} / \mathrm{min}$. The on-line analysis is carried out using a $\mathrm{C}_{18}$ analytical column with an acetonitrile gradient at $\mathrm{pH}$. The data are automatically evaluated, with the production of a report for compounds present at, or above, a certain concentration level between 1 and $3 \mu \mathrm{g} / \mathrm{L}$ [18]. The reproducibility of the retention times with a set of $25-30$ pesticides was excellent with a RSD value of $0.2-1.5 \%(n=20)$. At an analyte concentration of $1 \mu \mathrm{g} / \mathrm{L}$, the RSD of peak areas was in the range $1-15 \%$, with a new precolumn in each run. The highest RSD were observed only for analytes eluting between 12 and $25 \mathrm{~min}$ and were explained partly by matrix interferences and partly by breakthrough of the more basic compounds on the PLRP$\mathrm{S}$ cartridges [13]. The SAMOS system was made to act as an early warning system for use in the field. The robustness of the system was studied in two laboratories during 5- and 7 month periods. No major problem was encountered for over 1000 analyses, apart from the exchange of a deuterium lamp and clogging of the preconcentration system with nonfiltered waters.

\section{Quantitative analyses}

Several means of quantitation can be used. With on-line systems, it is not advisable to carry out quantitative analysis by comparison with direct injections. First, the volume of many injection loops is specified to an average accuracy of $20 \%$ and calibration of a loop is a rather delicate and time-consuming operation. This does not have to be considered with off-line procedures because the same loop is used for both analysis of unknown extracts and construction of calibration curves. Secondly, slight but imperceptible band-broadening may occur.

For the above reasons, any quantitation method (calibration curves, standard addition, etc.) should be performed using the whole procedure, i.e. with the same experimental conditions (same types of precolumns, sample volume, analytical column, and on-line gradient elution) as selected for the analysis of unknown water samples. Therefore, it is not necessary to know the recovery of the extraction process for each analyte. When possible, it is better to handle a samplevolume lower than the lowest breakthrough volume for more reproducible results. However, when multiresidue analyses are carried out, the sample volume is selected in order to detect most of the compounds at the required level. With a sample volume of $150 \mathrm{~mL}$ and using the Prospekt cartridges packed with PLRP-S, the recoveries of de-isopropyl- and deethyl-atrazine are not $100 \%$ because breakthrough has occurred on PLRPS, but it is possible to detect these compounds with reproducible results.

The calibration can be made by spiking LC-grade-, drinking-, surface- or other real water samples. In practice, especially in multiresidue analysis, it is easier to construct calibration curves once for all the analytes and to use them for any kind of water. It has been shown that calibration curves constructed with spiked LC-grade water samples and from spiked drinking water samples were similar [14]. Good linearity and correlation coefficients were obtained in the range $0.1-1.5 \mu \mathrm{g} / \mathrm{L}$. Calibration curves have also been constructed with surface waters and good linearity was obtained in the range $0.1-7 \mu \mathrm{g} / \mathrm{L}$. In surface water, the calibration curves depend on the interferences which show up in the real chromatogram and on the possibility of identifying the unknown peaks and their purity. In recent years, much attention has been given to identification and peak purity in diode-array software.

\section{Validation}

The most appropriate means for testing the accuracy of results given by an analytical procedure including a sample preatreatment should use natural matrix reference materials which are similar to environmental ground- or surfacewaters. These materials are now under study but are not yet available [37]. The actual quality control of analyses can only be performed through interlaboratory calibrations. Lacorte et al. [14,38,39] were the first to validate an automated on-line solid-phase extraction system for the first time by participating in the Aquacheck interlaboratory comparison study organized by the WRC (Medmenham, UK) where more conventional sample preparation methods and gas 
chromatographic determination were being used. The overall RSD between values obtained by the authors and the average value obtained by fourteen or fifteen other laboratories varied between 1.6 and $36 \%$ for atrazine and organophosphorus pesticides in finished drinking waters at levels ranging from 0.02 to $0.2 \mu \mathrm{g} / \mathrm{L}$.

\section{Application to various samples: Limits of determination}

The suitability of the SPE-LC-DAD system for multiresidue purposes is provided in figure 3 where metamitron was present in the groundwater at a concentration level of $0.12 \mu \mathrm{g} / \mathrm{L}$ and was just detected at $220 \mathrm{~nm}$ since this analyte was coeluted with an interfering hump [10]. However, the same

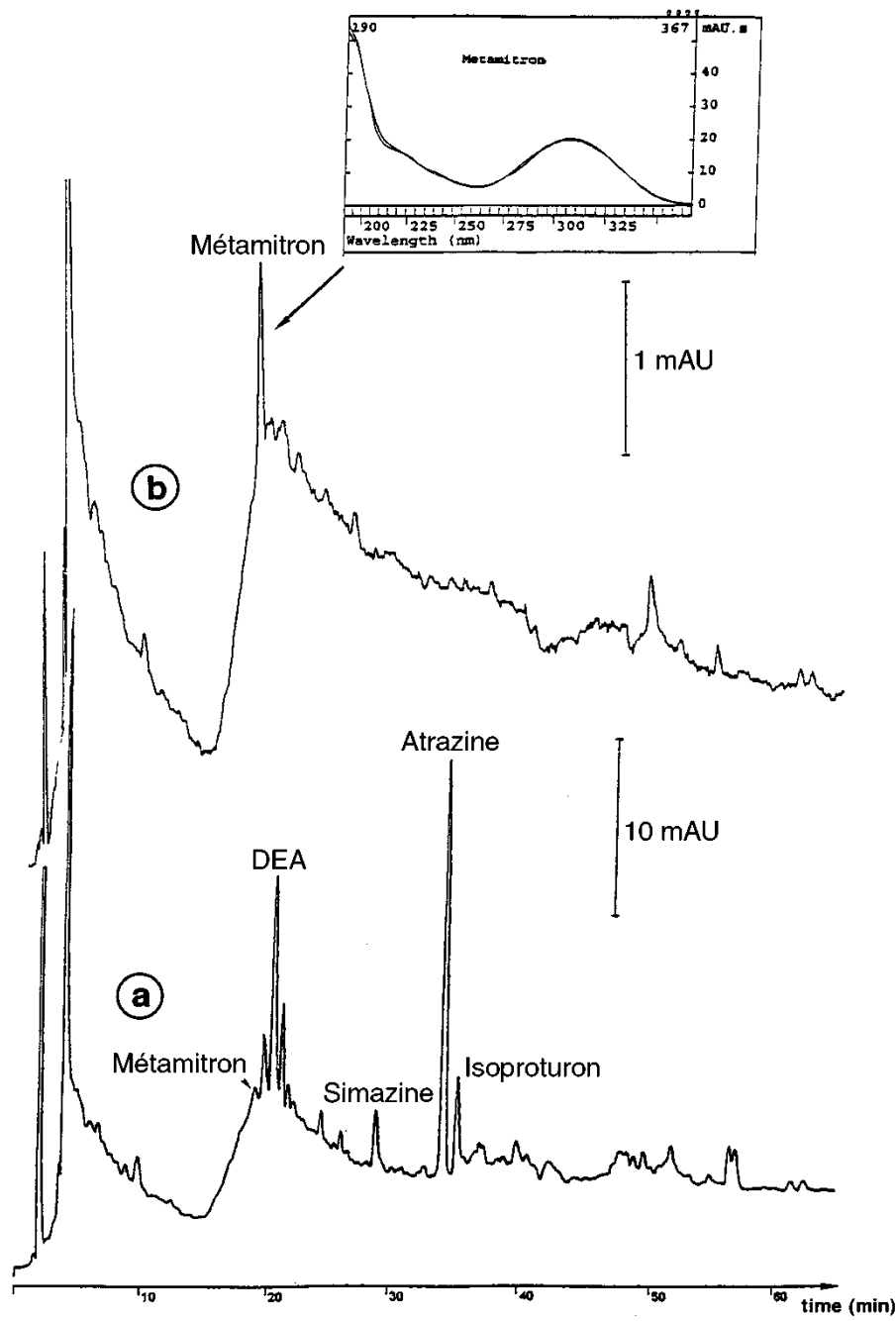

Figure 3. On-line analysis of $150 \mathrm{~mL}$ of a groundwater sample naturally contaminated with metamitron $(0.12 \pm 0.02 \mu \mathrm{g} / \mathrm{L})$, deethylatrazine, $(0.61 \pm 0.05 \mu \mathrm{g} / \mathrm{L})$, simazine $(0.05 \pm 0.01 \mu \mathrm{g} / \mathrm{L})$, atrazine $(0.42 \pm 0.03 \mu \mathrm{g} / \mathrm{L})$ and isoproturon $(0.48 \pm 0.03 \mu \mathrm{g} / \mathrm{L})$. Identification by retention time and by the match between spectra of the reference compound in a library and of the unknown peak. Quantitation using the MCA software of the DAD detector. Experimental conditions as in figure 2; chromatogram at $220 \mathrm{~nm}$ a) and at $306 \mathrm{~nm} \mathrm{~b}$ ). In the insert, confirmation of metamitron by the UV spectrum. From reference [2]. chromatogram drawn at $306 \mathrm{~nm}$ illustrates the low detection limit that can be reached for this analyte and the confirmation that can be provided by the DAD when the UV spectrum presents some characteristics in the scan range. It was possible to use a full scale of $1 \mathrm{mV}$, ten times lower than that at $220 \mathrm{~nm}$, because a very low background in the base line is detected at $306 \mathrm{~nm}$. Unfortunately, this property does not apply to all the pesticides.

In general, the limit of determination depends primarily on the detection mode and the properties (i.e. spectral properties) of the analytes, but also on the type and matrix of waters that are analysed. There is always a great difference (up to a factor of 10) between LODs obtained in LC-grade water and those obtained in ground- or drinking-waters. LODs in contaminated surface waters are also higher (about 5 times, depending on the organic carbon content) than those observed in drinking waters.

A survey of the results for many drinking- or groundwaters indicates that the limit of determination of $0.1 \mu \mathrm{g} / \mathrm{L}$ is easily obtained for most pesticides using UV detection and with the handling of $150-300 \mathrm{~mL}$ of sample. The LOD is often lower, around $10-30 \mathrm{ng} / \mathrm{L}$, which allows

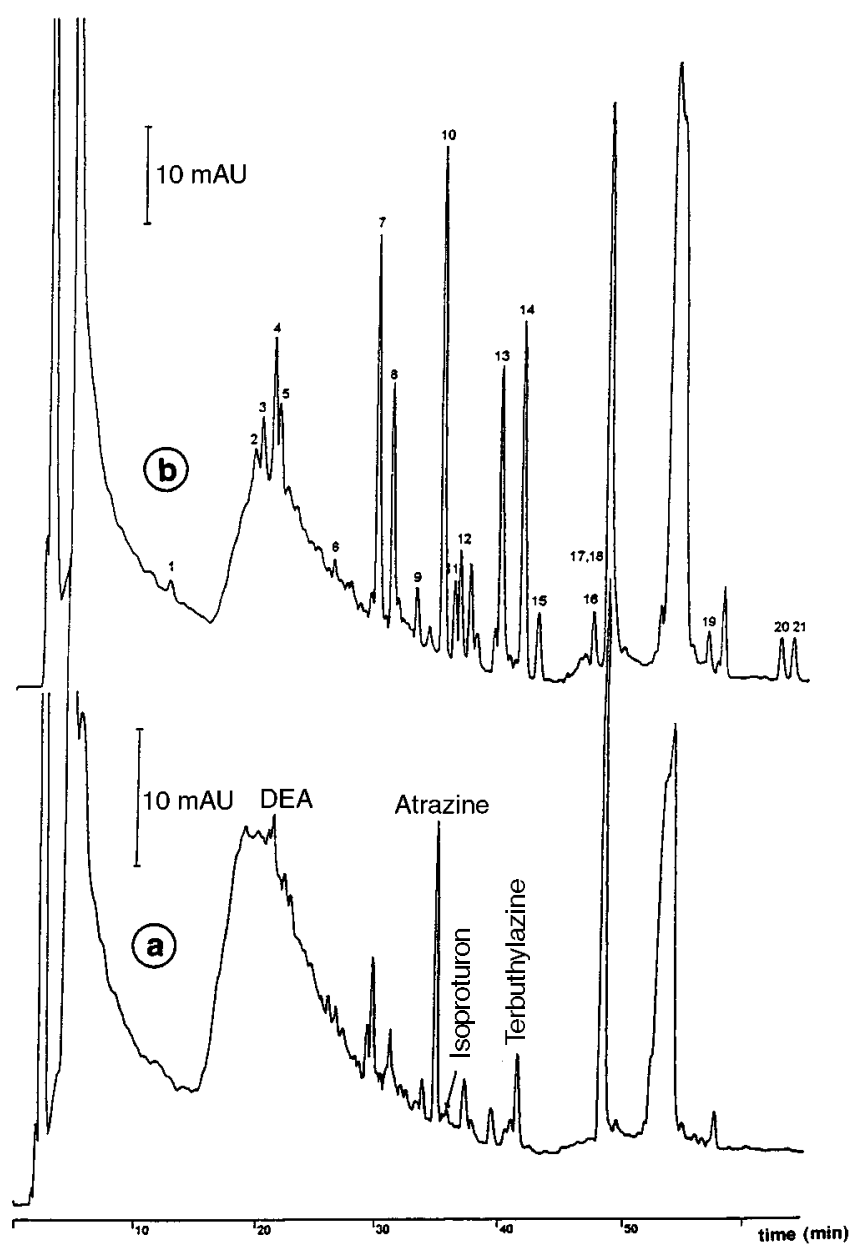

Figure 4. On-line analysis of $150 \mathrm{~mL}$ of, a) $150 \mathrm{~mL}$ of non-spiked river Marne water, and b) $150 \mathrm{~mL}$ of the same sample spiked with $0.5 \mu \mathrm{g} / \mathrm{L}$ of a miwture of 21 pesticides. Experimental conditions and peak identities as in figure 2.From reference [2]. 
quantitative analyses at the $0.1 \mu \mathrm{g} / \mathrm{L}$ level. Only the more polar compounds and/or degradation products such as deisopropylatrazine are difficult to determine at levels lower than $0.1 \mu \mathrm{g} / \mathrm{L}$. In surface waters, LOD of $0.1 \mu \mathrm{g} / \mathrm{L}$ can also be obtained, as can be estimated from figure 4 by the online analysis of a river Marne sample spiked with $0.5 \mu \mathrm{g} / \mathrm{L}$ of the same pesticides as the drinking water sample in figure 2 [2]. The chromatograms are very similar, the experimental conditions being the same apart from the attenuation range of the UV detector which is four times higher in figure 4. However, for many pesticides, the LODs are far below the $0.5 \mu \mathrm{g} / \mathrm{L}$ range, as can be seen from the height of some peaks at $220 \mathrm{~nm}$.

For the more polar range of compounds, the on-line system PGC/PGC could provide accurate determination of the more polar analytes. In a long-term survey of a ground-water source, monitoring using the PLRP-S precolumn and $\mathrm{C}_{18}$ analytical column on-line system indicated constant and rather high amounts of atrazine and de-ethylatrazine, with average concentrations of 0.5 and $0.6 \mu \mathrm{g} / \mathrm{L}$ respectively (see Fig. 3). Because of the bad detection obtained with this system for the second metabolite de-isopropylatrazine, a PGC precolumn-PGC analytical column coupling was used. Figure 5 shows the advantage of such a system, since deisopropylatrazine (DIA) is eluted after de-ethylatrazine (DEA) and can easily be delayed to $40 \mathrm{~min}$ in the chromatogram, after the interfering compounds [10]. The breakthrough volume of DIA on PGC is above $100 \mathrm{~mL}$ so that detection limits using $100 \mathrm{~mL}$ samples are in the low$0.1 \mu \mathrm{g} / \mathrm{L}$ range in LC-grade water, as shown in figures $5 \mathrm{a}, \mathrm{b}$. In the non-spiked ground water (Figs. 5c,d), DEA was confirmed at a concentration of $0.6 \mu \mathrm{g} / \mathrm{L}$ and the concentration of DIA was $0.05 \pm 0.01 \mu \mathrm{g} / \mathrm{L}$.

\section{Further developments}

Since many recent pesticides and/or degradation products cannot be analysed by GC, the only possibility of multiresidue analysis including compounds over a wide range of polarity is given by LC. On-line systems using LC can be fully automated and works as an early-warning or on-site monitoring system. They can also be used as a powerful routine tool in the laboratory. An automated post-column reaction can also be added to the on-line SPE-LC-UV DAD system, thus broadening the range of analyte analysed in one run. $N$-methyl carbamates and glyphosate can be thus determined.

The numerous applications of SPE-LC on-line systems have shown this method to be well suited for multiresidue analysis. Its wide acceptance has contributed greatly to the development of SPE-LC-MS systems, along with its identification potential.

\section{References}

1. Barceló, D.; Hennion, M. C. On-line sample strategies, In: Trace determination of pesticides and their degradation products in water, Elsevier, Amsterdam, NL, 1997; pp 357-422.

2. Barceló, D.; Hennion, M. C. Anal. Chim. Acta 1995, 318, 1.

3. Brouwer, E.; Kofman, U. A. Th.; Brinkman, U. A. Th. J. Chromatogr. A 1995, 703, 167.

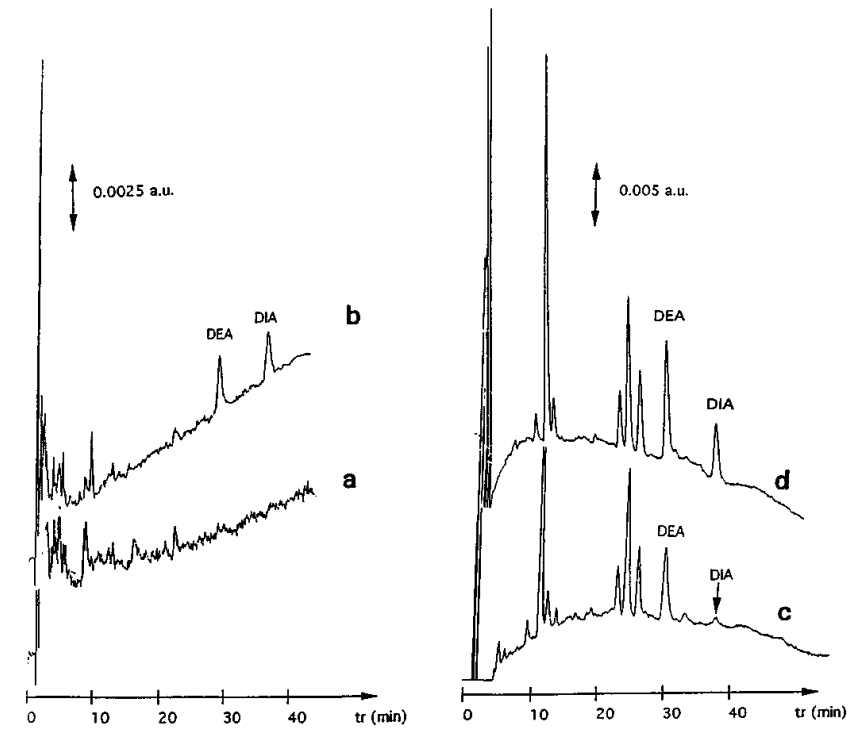

Figure 5. On-line preconcentration of different aqueous matrices using the on-line coupling of a PGC precolumn and PGC analytical column. Samples, a) $100 \mathrm{~mL}$ of non-spiked LC-grade water, b) spiked with $0.2 \mu \mathrm{g} / \mathrm{L}$ of DEA and DIA, c) $100 \mathrm{~mL}$ of non-spiked groundwater, d) spiked with $0.5 \mu \mathrm{g} / \mathrm{L}$ of DEA and DIA, Hypercarb column from Shandon, $10 \mathrm{~cm} \times 0.46 \mathrm{~cm}$ I.D., acetonitrile gradient with a $5 \times 10^{-3} \mathrm{M}$ phosphate buffer at $\mathrm{pH} 7,15 \%$ to $35 \%$ acetonitrile from 0 to $40 \mathrm{~min}$. Flow-rate: $1 \mathrm{~mL} / \mathrm{min} \mathrm{UV}$ detection at $220 \mathrm{~nm}$. From reference [10].

4. Brinkamn, U. A. Th. Environ. Sci. Technol. 1995, 29, 79A.

5. Nielen, M. W. F.; Frei, R. W.; Brinkman, U. A. Th. In: Selective Sample Handling and Detection in High Performance Liquid Chromatography, Frei, R. W.; Zech, K. Eds., Vol. 39, Elsevier, Amsterdam, 1988; p 5.

6. Font, G.; Manes, J.; Molto, J. C.; Pico, Y. J. Chromatogr. 1993, $642,135$.

7. Liska, I. J. Chromatogr. A 1993, 665, 163.

8. Brinkman, U. A. Th. J. Chromatogr. A 1994, 665, 217.

9. Hennion, M. C.; Pichon, V. Environ. Sci. Technol. 1994, 8, 576 A.

10. Dupas, S.; Guenu, S.; Pichon, V.; Montiel, A.; Welte, B.; Hennion, M. C. Intern. J. Environ. Anal. Chem. 1996, 65, 53.

11. Liska, I.; Brouwer, E. R.; Ostheimer, A. G. L.; Lingeman, H.; Brinkman, U. A. Th.; Geerdink, R. B.; Mulder, W. H. Int. J. Environ. Anal. Chem. 1992, 47, 267.

12. Slobodnik, J.; Brouwer, E. R.; Geerdink, R. B.; Mulder, W. H.; Lingeman, H.; Brinkman, U. A. Th. Anal. Chim. Acta 1992, $268,55$.

13. Slobodnik, J.; Groenewegen, M. G. M.; Brouwer, E. R.; Lingeman, H.; Brinkman, U. A. Th. J. Chromatogr. 1993, 642, 359.

14. Pichon, V.; Hennion, M. C. J. Chromatogr. A 1994, 665, 269.

15. Lacorte, S.; Barceló, D. Anal. Chim. Acta 1994, 296, 223.

16. Chiron, S.; Martinez, E.; Barceló, D. J. Chromatogr. A 1994, 665, 283.

17. Van Hout, P. J. M.; Brinkman, U. A. Th. Trends Anal. Chem. 1994, 13, 382.

18. Brinkman, U. A. Th.; Slobodnik, J.; Vreuls, J. J. Trends Anal. Chem. 1994, 13, 373.

19. Norberg, J.; Slobodnik, J.; Vreuls, J. J.; Brinkman, U. A. Th. Anal. Meth. Instrum. 1995, 2, 226. 
20. van Hout, P. J. M.; Hupe, K. P.; Vallet, G. Anal. Meth. Instrum. 1995, 2, 208.

21. Huen, J. M.; Mayer, A. G.; Baltensperger, B.; Kern, H. Fresenius' J. Anal. Chem. 1994, 348, 606.

22. Hennion, M. C.; Cau D. It Coumes, C.; Pichon, V. J. Chromatogr. A (in press).

23. Pichon, V.; Cau Dit Coumes, C.; Chen, L.; Guenu, S.; Hennion, M. C. J. Chromatogr. A 1996, 737, 169.

24. Guenu, S.; Hennion, M. C. J. Chromato gr. A 1996, 737, 15.

25. Guenu, S.; Hennion, M. C. Anal. Meth. Instrum. 1995, 2, 247.

26. Hennion, M. C.; Coquart, V.; Guenu, S.; C. Sella, C. J. Chromatogr. A 1996, 712, 287.

27. Guenu, S.; Hennion, M. C. J. Chromatogr. A 1994, 665, 243.

28. Coquart, V.; Hennion, M. C. J. Chromatogr. 1992, 600, 195.

29. Pichon, V.; Chen, L.; Guenu, S.; Hennion, M. C. J. Chromatogr. A 1995, 711, 257.
30. Nielen, M. W. F.; Brinkman, R. W.; Frei, R. W. Anal. Chem. 1985, 57, 806.

31. Pichon, V.; Hennion, M. C. Anal. Chim. Acta 1993, 284, 317.

32. Brouwer, E. R.; Liska, I.; Geerdink, R. B.; Frintrop, P. C. M.; Mulder, W. H.; Lingeman, H.; Brinkman, U. A. Th. Chromatographia 1991, 32, 445.

33. Coquart, V.; Hennion, M.-C. J. Chromatogr. 1991, 585, 67.

34. Nielen, M. W. F.; Jong, J.; Frei, R. W.; Brinkman, U. A. Th. Int. J. Environ. Anal. Chem. 1987, 25, 37.

35. Coquart, V.; Hennion, M. C. Sci. Total Environ. 1993, 132, 349.

36. Geerdink, R. B.; Van Balkom, C. A.; Brouwer, H. J. Chromatogr. 1986, 481, 275.

37. Ferrer, I.; Barceló, D. J. Chromatogr. A 1996, 737, 93.

38. Lacorte, S.; Barceló, D. J. Chromatogr. A 1996, 725, 85.

39. Lacorte, S.; Barceló, D. Environ. Sci. Technol. 1995, $29,2834$. 